\title{
Natural Language Indexing for Pedoinformatics
}

John Furey, Austin Davis, and Jennifer Seiter-Moser 
The U.S. Army Engineer Research and Development Center (ERDC) solves the nation's toughest engineering and environmental challenges. ERDC develops innovative solutions in civil and military engineering, geospatial sciences, water resources, and environmental sciences for the Army, the Department of Defense, civilian agencies, and our nation's public good. Find out more at www.erdc.usace.army.mil.

To search for other technical reports published by ERDC, visit the ERDC online library at https://erdclibrary.on.worldcat.org/discovery. 


\section{Natural Language Indexing for Pedoinformatics}

John Furey, Austin Davis, and Jennifer Seiter-Moser

Environmental Laboratory

U.S. Army Engineer Research and Development Center

3909 Halls Ferry Road

Vicksburg, MS 39180

Final report

Approved for public release; distribution is unlimited.

Prepared for U.S. Army Corps of Engineers

Washington, DC 20314

Under USACE Environmental Quality and Installations Program 


\section{Preface}

This project was supported by the U.S. Army Corps of Engineers (USACE) Environmental Quality and Installations Program at the U.S. Army Engineer Research and Development Center.

The work was performed by the Army's Engineer Research and Development Center, Environmental Laboratory (ERDC-EL). At the time of publication of this paper, the Deputy Director of ERDC-EL was Dr. Brandon Lafferty and the Director was Dr. Edmund J. Russo Jr.

This article was originally published online in the journal Geoderma on 1 August 2018.

The Commander of ERDC was COL Teresa A. Schlosser and the Director was Dr. David W. Pittman.

DISCLAIMER: The contents of this report are not to be used for advertising, publication, or promotional purposes. Citation of trade names does not constitute an official endorsement or approval of the use of such commercial products. All product names and trademarks cited are the property of their respective owners. The findings of this report are not to be construed as an official Department of the Army position unless so designated by other authorized documents. 


\title{
Natural language indexing for pedoinformatics
}

\begin{abstract}
A B S T R A C T
The multiple schema for the classification of soils rely on differing criteria but the major soil science systems, including the United States Department of Agriculture (USDA) and the international harmonized World Reference Base for Soil Resources soil classification systems, are primarily based on inferred pedogenesis. Largely these classifications are compiled from individual observations of soil characteristics within soil profiles, and the vast majority of this pedologic information is contained in non-quantitative text descriptions. We present initial text mining analyses of parsed text in the digitally available USDA soil taxonomy documentation and the Soil Survey Geographic database. Previous research has shown that latent information structure can be extracted from scientific literature using Natural Language Processing techniques, and we show that this latent information can be used to expedite query performance by using syntactic elements and part-of-speech tags as indices. Technical vocabulary often poses a text mining challenge due to the rarity of its diction in the broader context. We introduce an extension to the common English vocabulary that allows for nearly-complete indexing of USDA Soil Series Descriptions.
\end{abstract}

\section{Introduction}

Soil science can be considered settled science for basic agricultural applications (U.S. Department of Agriculture, 1951), but soil scientists have long struggled to extend their pedological techniques towards other soil functions (Wilding and Lin, 2006; Hartemink, 2006). Churchman (2010) applauded the increasing numbers of diverse publications involving the word "soil" in recent years, but reiterated that soil science per se deals with the formation and properties of soil (Brady and Weil, 2002). A fundamental observation is that soil formation is a complex set of processes with multiple factors (Jenny, 1941), and hence soil science terminology has to be complex to be useful (Bridges, 1997; Krasilnikov et al., 2009). The multiple time scales and the geospatial diversity of soil formation processes make it especially challenging to integrate them into a unified field of study (Baveye et al., 2011; Lin, 2011; Richter and Yaalon, 2012).

\subsection{Soil classification}

One type of product of soil science qua science is the development of soil groupings based upon similarities resulting from inferred formation processes. Alternative soil classifications focus on other aspects besides formation, such as suitability for construction engineering purposes in the Unified Soil Classification System (ASTM, 2017). Typically soil science groupings are arranged hierarchically (Nachtergaele et al., 2002) in the form of ranked levels of classification. In this work the terms soil classification level and soil taxonomy level are used interchangeably. For example in the widely-used United States Department of Agriculture (USDA) system there are 12 soil orders at the highest taxonomic level, and tens of thousands of soil series at the lowest level (Soil Survey Staff, 2014) which continues to gradually develop (Kimble et al., 1999). However despite the emphasis on soil formation processes soil classification systems are in no way cladistic, which is to say that originating "parent" soils are not placed at higher classification levels than further developed "child" soils.

In fact, soil classifications are derived by soil scientists primarily from consolidation of data from soil survey reporting and mapping, meaning that someone went to the location of a soil, described the soil in situ, and classified it based on soil scientists' criteria. These criteria depend on aggregates of soil sampling reports and to a far lesser extent laboratory geochemical and physical analyses, even though literally millions of soil samples have been characterized in the laboratory (Smith et al., 2014; National Cooperative Soil Survey, 2018; Davis et al., 2018). This expert system approach, along with the fact that pedogenesis is so tied to geography (Schaetzl and Thompson, 2015; Zinck et al., 2016), makes it difficult to generalize across disparate regions and to directly compare soil surveys from widely different areas, despite the increasing availability of such data (Beaudette and 
O'Geen, 2009). Adding to the degree of difficulty of inter-comparison, many different regions (e.g. countries) use quite different and at times competing classification systems (Duchaufour, 1988; Hewitt, 1992; Zitong, 1994; Isbell, 1996; Soil Classification Working Group, 1998; Ferg, 2001; Shishov et al., 2001). The main purpose of standing up the World Reference Base for Soil Resources soil classification system (International Union of Soil Sciences Working Group, 2015) was to harmonize these and other differently structured soil classification systems, not to translate between them.

Since approximately the middle of the 20th century, soil scientists have increasingly turned to numerical techniques to make soil classification more quantitative (Bidwell and Hole, 1964). These techniques have grown to include methods such as pedometrics (McBratney et al., 2000), geostatistics (Lark, 2012), geomatics (Davis et al., 2018), and taxonomic distance (Minasny et al., 2009; Láng et al., 2013). The success of each of these highly supervised techniques depends on the judicious selection of appropriate measures to discriminate and classify soils. Perhaps a more general term to use is pedoinformatics, the application of informatics techniques to soils data (Wilson, 2012). Pedoinformatics has been recently applied in the form of unsupervised multivariate cluster analyses to predict contaminant degradation and sorption in varied soils (Chappell et al., 2016; Katseanes et al., 2016).

\subsection{Scientific text mining}

In contrast to quantitative numerical data, resulting for example from laboratory measurements amenable to regular statistical analyses, most of the published information concerning soils is in the form of nonquantitative text i.e. words. The words themselves are not suitable for statistics designed for numbers, but are well suited for word ana-lyses including automated text mining techniques. Understandably, text mining was first approached systematically by library scientists (Deerwester et al., 1990). The techniques of general document text mining have become highly advanced in recent decades (Salton et al., 1994; Berry and Castellanos, 2007; Weiss et al., 2015). Notably, the publication of an efficient machine learning algorithm for text mining (Blei et al., 2003) led first to its main application in the analysis of general documents including newspaper archives (Wei and Croft, 2006), before being applied to technical and scientific documents (Blei and Lafferty, 2007).

Due principally to data availability, text mining continues to be applied primarily to analyses of general documents that use a common lexicon (Han et al., 2011; Liu et al., 2017), although methods of analyzing relationships between scientific documents, especially in authorship and references, are very actively researched (Bertin et al., 2013). The self-reflective world of scientometrics is beginning to see scientific text mining as a scientific activity in itself (Mayr and Scharnhorst, 2015). Since text mining is primarily taught in computer science departments, computer science literature often comprises a favorite target of analyses, and applications to internet text are especially scrutinized by computer scientists, and others, to discern social connections and shared intents as well as for other kinds of web analytics (Gupta and Lehal, 2009; Yu et al., 2010; Miner et al., 2012; Sun and Han, 2012; Kiritchenko et al., 2014; Wang and Han, 2015).

But by far the largest investment in scientific text mining in the past decade has involved the published biomedical literature. Biomedical terminology can be challengingly technical, and the analysis of biomedical word usage is its own field of study with its own journals (Shotton, 2010).The initial potential for biomedical discovery using unsupervised text mining methodology was recognized early (Jensen et al., 2006), and recent and ongoing work has been accomplishing much of the initial promise (El-Kishky et al., 2015; Ji et al., 2015; Gonzalez et al., 2016; Zhou and Fu, 2018). In fact the UK National Centre for Text Mining leverages its biomedical research support to further advance the study of scientific text mining methods (Brockmeier et al., 2017). To our knowledge, text mining pertaining specifically to soil science has not been previously published (Furey et al., 2017).

\section{Methods}

We chose to initially study the highly structured USDA soil taxonomy text documentation, including embedded user manuals and linked help files, and the text data entries in the National Cooperative Soil Survey (NCSS) characterization and Soil Survey Geographic (SSURGO) databases (National Cooperative Soil Survey, 2018; Soil Survey Staff, 2018). It would have been premature to instead start with analyses of the overall soil science literature, most of which exists in text forms that are unstructured or variously-structured including textbooks and journal articles. We obtained and prepared local copies of the NCSS and SSURGO databases on a workstation (Dell Precision 7810) running the Linux (Ubuntu 14.04) operating system. A local PostGIS (The PostGIS Development Group, 2018) implementation (PostGIS 2.1.10) housed the text data for custom database queries.

The Python (Python Core Team, 2018) language framework (Python 3.4.6) was used to execute the database queries and calls to Natural Language Processing (NLP) (Bird et al., 2009) modules from gensim (Rehurek and Sojka, 2010; Rehurek, 2018) for topic modelling (gensim 1.0.1) and from the Natural Language Toolkit (NLTK) (Bird, 2017) for word tagging (NLTK 3.2.5). Due to the complexity of the structures revealed by text mining of the database documentation files (Fig. 1), we determined that a more quickly productive focus of this initial investigation would be the set of USDA Soil Series Descriptions.

The local databases contained 16,599 uniquely named soil series as extant in the USDA taxonomy, and these text data were parsed to paragraphs operationally defined by whitespaces. A portion of one of the soil series entries is shown in Fig. 2. Many of the words in these entries are common English words as used in the general English lexicon (e.g. "somewhat"), and other words that are essentially solely soil science terminology ("superactive"), but many other words are common English words imbued with soil science significance by usage and context ("fine sand"). Taken together, a technical inventory of certain lexemes for soil science can be extended from common English using English morphemes and idiomatic expressions, and thereby generate a wordstock of soils-related terminology and technical parts of speech.

To initialize a training set to perform scientific text mining, we first ran 38 paragraphs randomly chosen from the soil series entries through the default NLTK stochastic part-of-speech tagger (the maxent_treebanck_pos_tagger model). As might have been expected, most of the words were not properly tagged on the first pass since the default tags had been developed for non-technical texts. For an example using just the default tags, the word "mixed" was unfailingly tagged as VBD (indicating a past tense verb) instead of its actual functioning as JJ (adjective). This improper tagging of ordinary words was undoubtedly due to the dissimilarity of usage and context between the soil series texts and the default tagger corpus, but certainly another large cause of the wrong tagging was the uniquely technical vocabulary. This failure to appropriately tag vocabulary in a technical context motivated the authors to refine and extend the part-of-speech tagset to enable technical word indexing.

We manually tagged the initial set of 38 paragraphs by an extension of the NLTK tagset using custom technical word tags, two being generically technical tags such as MM (related to measurements), and a dozen others being tags denoting specifically soil science technical usage such as SP (soil property) and PGM (physiographic modifier). Tagging technical words in this manner enabled direct lookup of specifically tagged technical words and groupings. We highlight the fact that a large fraction of the words in each soil series description involved properties of the location in which the soil was found, which we designated as physiographic words, while other words described properties of the soil itself. Table 1 exhibits the complete list of tags used to extend the NLTK tagset. 


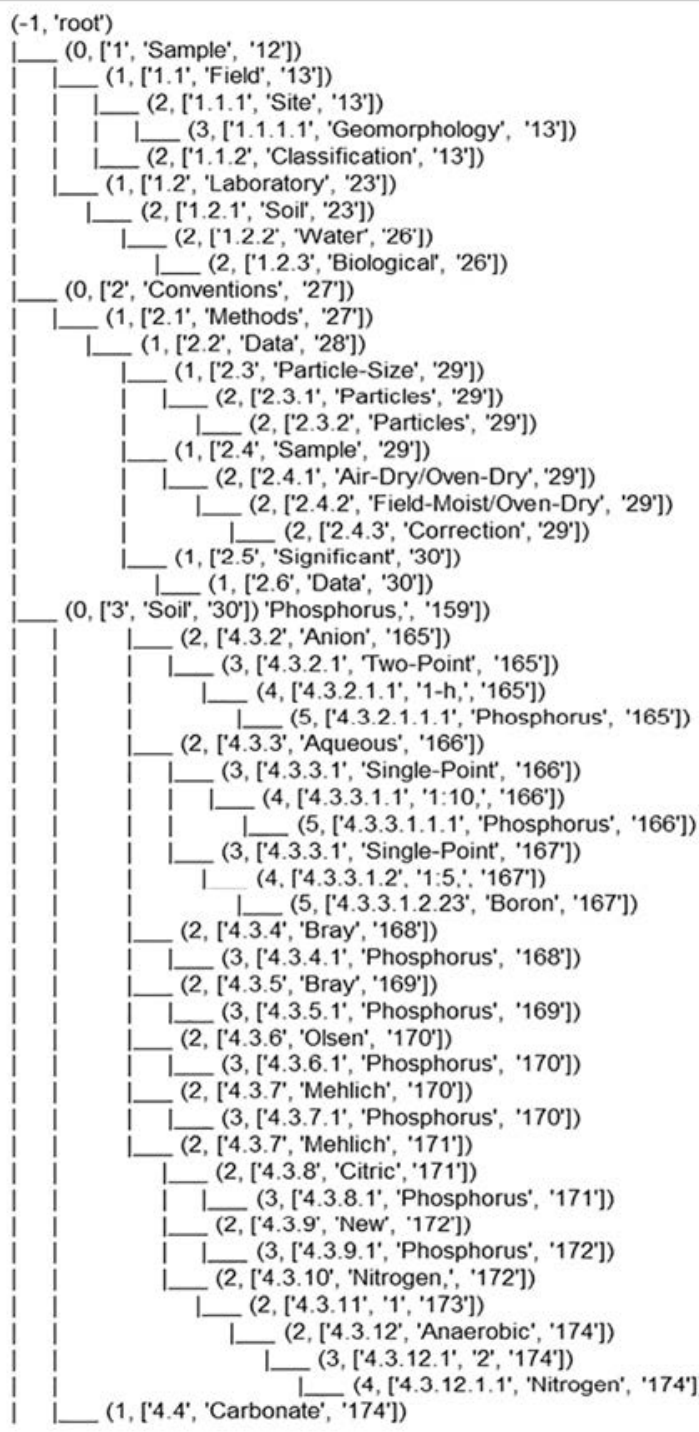

Fig. 1. A semantic analysis tree structure of a portion of the first page of the NCSS database user manual.
Table 1

Technical tags in the extended tagset.

\begin{tabular}{lll}
\hline Tag & Meaning & Example \\
\hline MM & Measure modifier & Annual \\
MU & Measure unit & Degree \\
PGL & Physiography location & Piedmont \\
PGM & Physiography modifier & Flood \\
PGN & Physiography noun & Plateau \\
PGP & Physiography property & Slope \\
SCM & Soil color modifier & Reddish \\
SDM & Soil depth modifier & Shallow \\
SDN & Soil depth noun & Depth \\
SNM & Soil noun modifier & Geological \\
SNN & Soil noun & Sediments \\
SNNP & Soil proper noun & MEMPHIS \\
SP & Soil property & Permeable \\
SPM & Soil property modifier & Moderately \\
\hline
\end{tabular}

The small initial training set was then used to bootstrap iterative machine learning for technical text mining, resulting in an enlarged (but still small compared to common English document corpuses) technical corpus comprising paragraphs randomly chosen from the soil series entries. Briefly, the NLP text mining procedure as implemented would examine the technical corpus first, then fall back to the default nontechnical corpus, and if it still could not determine an appropriate tag then the procedure would label it XX (unknown, or considered untagged) in order to make it easy to find (and count) untagged words.

\section{Results}

The strictly unigram (words considered in isolation, such as "poorly") performance of technical word tagging was still poor for the enlarged corpus, but the bigram (words considered in pairs, such as "poorly drained") performance converged rapidly as the training corpus enlarged from the initial 38 paragraphs (Fig. 3).

An example output of the tagging procedure, using bigram tagging with a training corpus of 160 soil series paragraphs, is illustrated in Fig. 4.

When up to 500 paragraphs were included in the training corpus, the bigram tagging rate averaged $98.78 \%$ as tested against a set of 1000 soil series paragraphs not in the corpus. The trigram performance was not significantly different at $98.80 \%$ tagging rate. A manual examination of some of the remaining untagged words revealed that the tagger correctly did not tag them, because those untagged words were rare one-offs including location names and other proper nouns not used in

\section{LOCATION FISK, WI}

The Fisk series consists of very deep, somewhat poorly drained soils formed in a mantle of sandy outwash or lacustrine deposits and in the underlying silty and loamy outwash or lacustrine deposits on glacial lake basins and on terraces. Slope ranges from 0 to 3 percent. Mean annual precipitation is about $711 \mathrm{~mm}$ ( 28 inches). Mean annual air temperature is about 8.9 degrees $\mathrm{C}$ ( 48 degrees $\mathrm{F}$ ).

TAXONOMIC CLASS: Sandy over loamy, mixed, superactive, mesic Aquic Dystric Eutrudepts

TYPICAL PEDON: Fisk loamy fine sand - on a west-facing, convex slope of 2 percent cropped to corn at an elevation of about 238 meters (783 feet) above man sea level. (Colors are for moist soil unless otherwise stated.) Ap--0 to $23 \mathrm{~cm}$ (0 to 9 inches); very dark brown (10YR 2/2) loamy fine sand, grayish brown (10YR 5/2) dry; weak fine subangular blocky structure; very friable; common fine roots; neutral; abrupt smooth boundary. [18 to $23 \mathrm{~cm}$ (7 to 9 inches) thick] Bw1--23 to $61 \mathrm{~cm}$ (9 to 24 inches); brown (10YR 4/3) fine sand with large pockets or discontinuous layers of grayish brown (10YR 5/2) fine sand in lower 10 inches; single grain; loose; common fine roots; common very dark brown (10YR 2/2) worm casts in upper $8 \mathrm{~cm}$ (3 inches); common fine prominent red (2.5YR 4/6) and common medium prominent strong brown (7.5YR 5/6) masses of oxidized iron

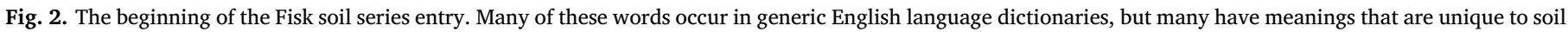
science. 


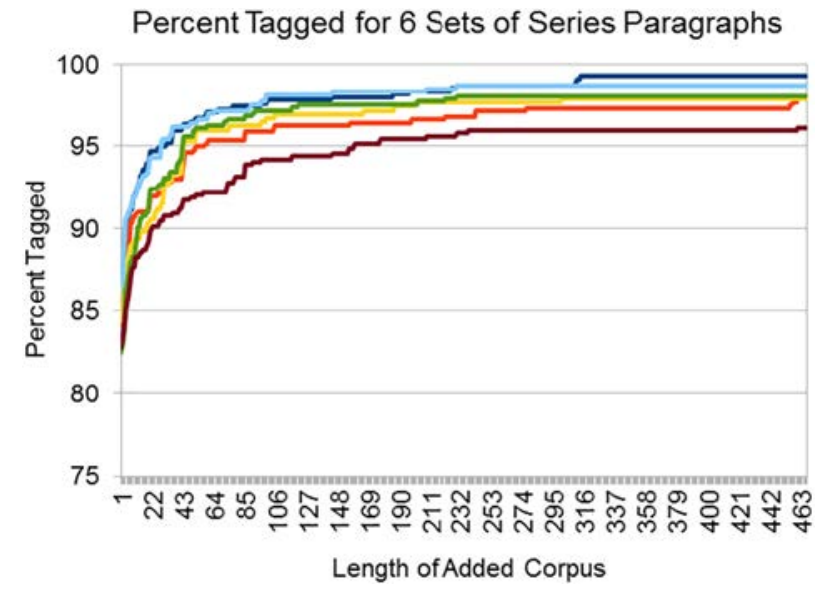

Fig. 3. The performance of the bigram tagging procedure typically began to saturate at above 95\% tagging rate when the training corpus began to exceed approximately 100 entries.

any other entries, as well as odd abbreviations and the occasional evident technical misspellings and other obvious typographical errors. Because of the unitarity of these rare words, this kind of sparsity problem is not helped by, and indeed can be exacerbated by, simply enlarging the corpus further.

Due to the random selection for the training corpus amongst all the entries at the soil series level, the tag rate was unrelated to the taxonomic distance between soil series. What that means is simply that the technical words used in the soil series descriptions, even if they could be considered obscure in other contexts, were at least consistently used at the soil series level. This aspect also justifies our fundamental assumption that a soil science lexicon exists separately from common language but can be treated as an extension of it by using natural language programming tools.

The performance of a tagger trained on soil series paragraphs was also tested against paragraphs randomly chosen from descriptions of higher levels in the soil taxonomy. The bigram tagging rate of 1000 other taxonomy paragraphs, using a training corpus of 160 soil series paragraphs, averaged $81.04 \%$. A manual examination showed, again unsurprisingly, that many different words were used in these different types of paragraphs. For example the soil great group words "Eutrudepts" and "Dystrusterts" never occurred in any of the soil series paragraphs.

\section{Conclusions and suggestions}

It should be emphasized that the NLP machine learning procedure as implemented is syntactically naïve, having absolutely no lexical heuristics. For an extreme but highly illustrative example, in Fig. 4 the singular form "basin" had indeed occurred in that particular corpus but there was no rule to recognize the plural form. We believe the bootstrapping of the machine learning on the technical language entries makes it relatively insensitive to the size and content of the fallback generic language corpus, as also evidenced by the rapid saturation of the tagging performance. We believe the fact that the trigram performance was the same as the bigram performance reflects the terseness, or stylelessness, of the technical descriptions in the soil series paragraphs. What is essentially overtraining on style is often a desired feature of NLP for general documents, for example for determining authorship, but would be an unwelcome bug in technical word feature analyses.

Perhaps the most obvious immediate improvement for the current work would require a fallback technical language corpus, for example using a soil science lexicon or encyclopedia compiled by consensus of soil scientists, as well as incorporating some other specialized language such as location names that are not specifically soil science words in themselves. Semi-supervised learning of word embeddings could also more directly incorporate soil science knowledge (Simova and Uszkoreit, 2017) than black-box machine learning. It is possible that relatively simple heuristics would enable autorecognition of polynouns and other modular words, since concatenation is evidently a favorite lexical tool of soil science, and thereby also aid inter-taxonomic level text mining. Then there is the possibility that unsupervised machine learning applied to the broader soil science literature could itself accomplish the compilation of a soil science lexicon or encyclopedia, but that larger effort is beyond our expected resources. We hope to spark the use of text mining methods in many soil science applications.

One suggested application of this work is eventually helping prepare soil mixtures or soil substitutes. As a related example, although the normal use of the USDA soil texture triangle (Natural Resources Conservation Service, 2012) is to classify a soil based on the relative numerical amounts of sand, silt, and clay components, a valid alternative application is predicting numerical recipes for preparing textures using particular proportions of other textures. It should be noted that there is no standard translation of soil texture words for engineering purposes (Tingle et al., 2016), although research continues into the numerical correlations between differing soil engineering classification schema (Zakikhani et al., 2017). A similar concept is employed in spectral mixture analyses for remote sensing purposes (Bayer et al., 2012). We expect that some soils of interest can be effectively combined to achieve particular results based on pedoinformatic analyses of their text descriptions.

A more directly influential application would apply similar methodologies to soil science documents in other languages where much soils information also exists in mostly descriptive text form. Suggested languages would include French, especially in the French Soil Reference System (Duchaufour, 1988) and the extensive French contributions to the World Reference Base for Soil Resources soil classification system. It is expected that similar latent syntactic structures could be formed through small extensions of French parts-of-speech analyses to establish indicial structures complementary to those formed by the results of our USDA technical word analysis. If the relations between such latent structures in scientific descriptions can be established, it is possible that translations between different soil taxonomies could be effected in nonlanguage-specific dimensions and then reduced to language-specific vocabularies that could be directly understood by local language soil

\footnotetext{
The/DT Fisk/SNNP series/SNN consists/VBZ of/IN very/JJ deep/SDM ,/, somewhat/JJ poorly/SPM drained/SP soils/SNNS formed/VBN in/IN a/DT mantle/XX of/IN sandy/PGM outwash/PGN or/CC lacustrine/PGM deposits/PGNS and/CC in/IN the/DT underlying/VBG silty/PGM and/CC loamy/PGM outwash/PGN or/CC lacustrine/PGM deposits/PGNS on/IN glacial/PGM lake/PGM basins/XX and/CC on/IN terraces/PGNS. Slope/PGP ranges/MM from/IN 0/CD to/TO 3/CD percent/MU. Mean/MM annual/MM precipitation/PGP is/VBZ about/IN 711/CD mm/MU (/( 28/CD inches/MU )/). Mean/MM annual/MM air/PGM temperature/PGP is/VBZ about/IN 8.9/CD degrees/MU C/MM (/( 48/CD degrees/MU F/MM )/).
}

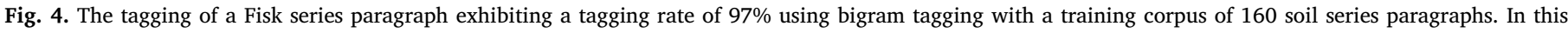
example the words "mantle" and "basins" had simply not occurred in that particular corpus. 
scientists.

\section{Acknowledgements}

Funding: This work was supported by the Environmental Quality and Installations program at the U.S. Army Engineer Research and Development Center, Vicksburg, MS.

\section{References}

ASTM Standard D2487-17, 2017. Standard Practice for Classification of Soils for Engineering Purposes (Unified Soil Classification System). ASTM International, West Conshohocken, PA.

Baveye, P., Rangel, D., Jacobson, A., Laha, M., Darnault, C., Otten, W., Radulovich, R., Camargo, F., 2011. From dust bowl to dust bowl: soils are still very much a frontier of science. Soil Sci. Soc. Am. J. 75, 2037-2048.

Bayer, A., Bachmann, M., Müller, M., Kaufmann, H., 2012. A comparison of feature-based MLR and PLS regression techniques for the prediction of three soil constituents in a degraded south African ecosystem. Appl. Environ. Soil Sci. 971252, 1-20.

Beaudette, D., O'Geen, A., 2009. Soil-Web: an online soil survey for California, Arizona, and Nevada. Comput. Geosci. 35, 2119-2128.

Berry, M., Castellanos, M. (Eds.), 2007. Survey of text mining: clustering, classification, and retrieval, 2nd edition. .

Bertin, M., Atanassova, I., Larivière, V., Gingras, Y., 2013. The distribution of references in scientific papers: an analysis of the IMRaD structure. In: Proc. 14th International Society for Scientometrics and Informetrics Conference. Austria, Vienna.

Bidwell, O., Hole, F., 1964. Numerical taxonomy and soil classification. Soil Sci. 97, $58-62$.

Bird, S., 2017. NLTK Documentation, Release 3.2.5. https://www.nltk.org/genindex. html, Accessed date: 24 January 2018.

Bird, S., Klein, E., Loper, E., 2009. Natural Language Processing with Python. O'Reilly Media, Inc., Sebastopol, CA.

Blei, D., Lafferty, J., 2007. A correlated topic model of Science. Ann. Appl. Stat. 1, 17-35.

Blei, D., Ng, A., Jordan, M., 2003. Latent Dirichlet allocation. J. Mach. Learn. Res. 3, 993-1022.

Brady, N., Weil, R., 2002. The Nature and Properties of Soils, 13th edition. Prentice Hall, Upper Saddle River, NJ.

Bridges, E., 1997. Origins, adoption, and development of soil horizon designations. Adv. Geoecol. 29, 47-65.

Brockmeier, A., Mu, T., Ananiadou, S., Goulermas, J., 2017. Quantifying the informativeness of similarity measurements. J. Mach. Learn. Res. 18, 1-61.

Chappell, M., Seiter-Moser, J., West, H., Negrete, M., Porter, B., Price, C., Miller, L., 2016. A pedo-informatic approach for universal predictions of complex soil environmental processes. In: Proc. 24th International Conference on Geoinformatics. Ireland, Galway.

Churchman, G., 2010. The philosophical status of soil science. Geoderma 157, 214-221.

Davis, A., Furey, J., Seiter-Moser, J., 2018. Taxonomic Soils Geomatics Investigation. In: ERDC Technical Note. U.S. Army Engineer Research and Development Center, Vicksburg, MS (in press).

Deerwester, S., Dumais, S., Landauer, T., Furnas, G., Harshman, R., 1990. Indexing by latent semantic analysis. J. Am. Soc. Inf. Sci. 41, 391-407.

Duchaufour, P., 1988. Abrégé de Pédologie, 2nd edition. Masson, Paris.

El-Kishky, A., Song, Y., Wang, C., Voss, C., Han, J., 2015. Scalable topical phrase mining from text corpora. In: Proceedings of the Very Large Data Base Endowment. 8. pp. 305-316.

Ferg, L. (Ed.), 2001. Chinese Soil Taxonomy. Science Press, Beijing.

Furey, J., Davis, A., Seiter-Moser, J., 2017. Pedoinformatics approach to soil text analytics. In: Proc. American Geophysical Union Fall Meeting. New Orleans, LA.

Gonzalez, G., Tahsin, T., Goodale, B., Greene, A., Greene, C., 2016. Recent advances and emerging applications in text and data mining for biomedical discovery. Brief. Bioinform. 17, 33-42.

Gupta, V., Lehal, G., 2009. A survey of text mining techniques and applications. J. Emerg. Technol. Web Intel. 1, 60-76.

Han, J., Kamber, M., Pei, J., 2011. Data Mining: Concepts and Techniques, 3rd edition. Morgan Kaufmann Publishers, Burlington, MA.

Hartemink, A. (Ed.), 2006. The Future of Soil Science. International Union of Soil Sciences, Wageningen, Netherlands.

Hewitt, A., 1992. New Zealand Soil Classification. In: Land Resources Scientific Report No. 19. Department of Scientific and Industrial Research, Lower Hutt, New Zealand.

International Union of Soil Sciences Working Group, 2015. World Reference Base for Soil Resources 2014, update 2015. In: World Soil Resources Reports No. 106. Food and Agriculture Organization of the United Nations, Rome, Italy.

Isbell, R.F., 1996. The Australian Soil Classification. Australian Soil and Land Survey Handbook. Commonwealth Scientific and Industrial Research Organisation, Canberra, Australia.

Jenny, H., 1941. Factors of Soil Formation. McGraw-Hill, New York, NY.

Jensen, L., Saric, J., Bork, P., 2006. Literature mining for the biologist: from information retrieval to biological discovery. Nat. Rev. Genet. 7, 119-129.

Ji, M., He, Q., Han, J., Spangler, S., 2015. Mining strong relevance between heterogeneous entities from unstructured biomedical data. Data Min. Knowl. Disc. 29, 976-998.

Katseanes, C., Chappell, M., Hopkins, B., Durham, B., Price, C., Porter, B., Miller, L., 2016. Multivariate functions for predicting the sorption of 2,4,6-trinitrotoluene (TNT) and 1,3,5-trinitro-1,3,5-tricyclohexane (RDX) among taxonomically distinct soils. J. Environ. Manag. 182, 101-110.

Kimble, J., Ahrens, R., Bryant, R. (Eds.), 1999. Classification, Correlation and Management of Anthropogenic Soils. National Soil Survey Center, Lincoln, NE.

Kiritchenko, S., Zhu, X., Mohammad, S., 2014. Sentiment analysis of short informal texts. J. Artif. Intell. Res. 50, 723-762.

Krasilnikov, P., Ibanez Martí, J.-J., Arnold, R., Shoba, S. (Eds.), 2009. Handbook of Soil Terminology, Correlation and Classification. Earthscan, London, UK.

Láng, V., Fuchs, M., Waltner, I., Michéli, M., 2013. Soil taxonomic distance, a tool for correlation: as exemplified by the Hungarian Brown Forest Soils and related WRB Reference Soil groups. Geoderma 192, 269-276.

Lark, R., 2012. Towards soil geostatistics. Spatial Statistics 1, 92-99.

Lin, H., 2011. Three principles of soil change and pedogenesis in time and space. Soil Sci. Soc. Am. J. 75, 2049-2070.

Liu, J., Shang, J., Han, J., 2017. Phrase Mining from Massive Text and its Applications. Morgan \& Claypool Publishers, Williston, VT.

Mayr, P., Scharnhorst, A., 2015. Scientometrics and information retrieval - weak links revitalized. Scientometrics 102, 2193-2199.

McBratney, A., Odeh, I., Bishop, T., Dunbar, M., Shatar, T., 2000. An overview of pedometric techniques for use in soil survey. Geoderma 97, 293-327.

Minasny, B., McBratney, A., Hartemink, A., 2009. Global pedodiversity, taxonomic distance, and the World Reference Base. Geoderma 155, 132-139.

Miner, G., Elder, J., Fast, A., Hill, T., Nisbet, R., Delen, D., 2012. Practical Text Mining and Statistical Analysis for Non-structured Text Data Applications. Academic Press, Cambridge, MA.

Nachtergaele, F., Berding, F., Deckers, J., 2002. Pondering hierarchical soil classification systems. In: Michele, E., Nachtergaele, F., Jones, R., Montanarella, L. (Eds.), Soil Classification. European Soil Bureau Research Report 7, Luxembourg, pp. 71-79.

National Cooperative Soil Survey, 2018. National Cooperative Soil Survey Characterization Database. http://ncsslabdatamart.sc.egov.usda.gov, Accessed date: 24 January 2018.

Natural Resources Conservation Service, 2012. Engineering classification of Earth materials, Chapter 3. In: National Engineering Handbook, Part 631, 210-VI-NEH, Amendment 55. U.S. Department of Agriculture, Washington, DC.

Python Core Team, 2018. Python: A dynamic, open source programming language. Python Software Foundation. https://www.python.org, Accessed date: 24 January 2018.

Rehurek, R., 2018. https://radimrehurek.com/gensim/index.html. Accessed Wednesday, January 24, 2018.

Rehurek, R., Sojka, P., 2010. Software framework for topic modelling with large corpora. In: Proc. LREC 2010 Workshop on New Challenges for NLP Frameworks, pp. 45-50.

Richter, D., Yaalon, D., 2012. "The changing Model of Soil" revisited. Soil Sci. Soc. Am. J. 76, 766-778.

Salton, G., Allan, J., Buckley, C., Singhal, A., 1994. Automatic analysis, theme generation, and summarization of machine-readable texts. Science 264, 1421-1426.

Schaetzl, R., Thompson, M., 2015. Soils: Genesis and Geomorphology, 2nd edition. Cambridge University Press, Cambridge, UK.

Shishov, L., Tonkonogov, V., Lebedeva, I., Gerasimova, M., 2001. Russian Soil Classification System. V.V. Dokuchaev Soil Science Institute, Moscow, Russia.

Shotton, D., 2010. CiTO, the Citation Typing Ontology. J. Biomed. Semantics 1, S6.

Simova, I., Uszkoreit, H., 2017. Word embeddings as features for supervised coreference resolution. In: Proc. Recent Advances in Natural Language Processing, Varna, Bulgaria, pp. 686-693.

Smith, D., Cannon, W., Woodruff, L., Solano, F., Ellefsen, K., 2014. Geochemical and mineralogical maps for Soils of the Conterminous United States. In: Open-File Report 2014-1082, U.S. Geological Survey. U.S. Department of the Interior, Washington, DC.

Soil Classification Working Group, 1998. In: 3rd edition (Ed.), The Canadian System of Soil Classification. Agriculture and Agri-Food Canada, Ottawa, Canada Publication 1646.

Soil Survey Staff, 2014. Keys to Soil Taxonomy, 12th edition. In: Natural Resources Conservation Service. U.S. Department of Agriculture, Washington, DC.

Soil Survey Staff, 2018. Natural Resources Conservation Service, U.S. Department of Agriculture, Soil Survey Geographic (SSURGO) Database. https://sdmdataaccess.sc. egov.usda.gov, Accessed date: 24 January 2018.

Sun, Y., Han, J., 2012. Mining Heterogeneous Information Networks: Principles and Methodologies. Morgan \& Claypool Publishers, Williston, VT.

The PostGIS Development Group, 2018. https://postgis.net/documentation/, Accessed date: 24 January 2018

Tingle, J., Tingle, S., Harrelson, D., 2016. Translating the language of soils: developing a soil classification system for international engineering projects. GEO-STRATA 20, 48-52.

U.S. Department of Agriculture, 1951. Soil survey manual. In: Agricultural Handbook No. 18. U.S. Government Printing Office, Washington, DC.

Wang, C., Han, J., 2015. Mining Latent Entity Structures. Morgan \& Claypool Publishers, Williston, VT.

Wei, X., Croft, B., 2006. LDA-based document models for ad-hoc retrieval. In: Proc. SIGIR'06, Seattle, WA, pp. 178-185.

Weiss, S., Indurkhya, N., Zhang, T., 2015. Fundamentals of Predictive Text Mining, 2nd edition. Springer-Verlag, London, UK.

Wilding, L., Lin, H., 2006. Advancing the frontiers of soil science towards a geoscience. Geoderma 131, 257-274.

Wilson, P., 2012. Advancing online delivery of Australian soil data and information. Black Mountain Laboratories. Commonwealth Scientific and Industrial Research Organisation, Canberra, Australia.

Yu, P., Han, J., Faloutsos, C. (Eds.), 2010. Link Mining: Models, Algorithms, and Applications, Springer. NY, New York. 
Zakikhani, M., Gidley, P., Tingle, J., 2017. Development of an Engineering Soil Database. In: ERDC TR 17-15. U.S. Army Engineer Research and Development Center, Vicksburg, MS.

Zhou, J., Fu, B., 2018. The research on gene-disease association based on text-mining of PubMed. BMC Bioinf. 19, 37-45.
Zinck, J., Metternicht, G., Bocco, G., Del Valle, H., 2016. Geopedology. Springer International Publishing, Switzerland.

Zitong, G. (Ed.), 1994. Chinese Soil Taxonomic Classification. Institute of Soil Science, Academia Sinica, Taipei. 


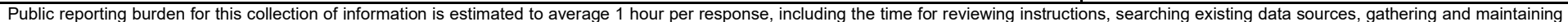

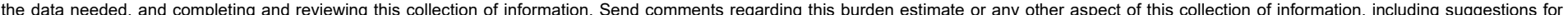

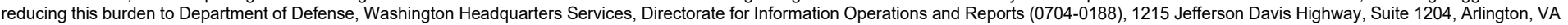

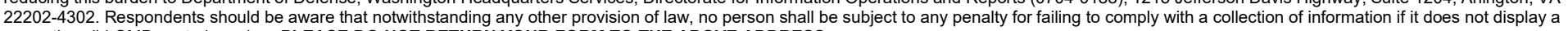
currently valid OMB control number. PLEASE DO NOT RETURN YOUR FORM TO THE ABOVE ADDRESS.
1. REPORT DATE (DD-MM-YYYY)
2. REPORT TYPE
September 2021
Final

4. TITLE AND SUBTITLE

Natural Language Indexing for Pedoinformatics

3. DATES COVERED (From - To)

5a. CONTRACT NUMBER

5b. GRANT NUMBER

5c. PROGRAM ELEMENT NUMBER

6. AUTHOR(S)

5d. PROJECT NUMBER

John Furey, Austin Davis, and Jennifer Seiter-Moser

5e. TASK NUMBER

5f. WORK UNIT NUMBER

7. PERFORMING ORGANIZATION NAME(S) AND ADDRESS(ES)

Environmental Laboratory

U.S. Army Engineer Research and Development Center

3909 Halls Ferry Road

Vicksburg, MS 39180

9. SPONSORING / MONITORING AGENCY NAME(S) AND ADDRESS(ES)

U.S. Army Corps of Engineers

Washington, DC 20314

8. PERFORMING ORGANIZATION REPORT
NUMBER

ERDC/EL MP-21-12

10. SPONSOR/MONITOR'S ACRONYM(S)

11. SPONSOR/MONITOR'S REPORT NUMBER(S)

\section{DISTRIBUTION / AVAILABILITY STATEMENT}

Approved for public release; distribution is unlimited.

13. SUPPLEMENTARY NOTES

This article was originally published online in the journal Geoderma on 1 August 2018.

This work was supported by the Environmental Quality and Installations Program at the U.S. Army Engineer Research and

Development Center.

\section{ABSTRACT}

The multiple schema for the classification of soils rely on differing criteria but the major soil science systems, including the United States Department of Agriculture (USDA) and the international harmonized World Reference Base for Soil Resources soil classification systems, are primarily based on inferred pedogenesis. Largely these classifications are compiled from individual observations of soil characteristics within soil profiles, and the vast majority of this pedologic information is contained in nonquantitative text descriptions. We present initial text mining analyses of parsed text in the digitally available USDA soil taxonomy documentation and the Soil Survey Geographic database. Previous research has shown that latent information structure can be extracted from scientific literature using Natural Language Processing techniques, and we show that this latent information can be used to expedite query performance by using syntactic elements and part-of-speech tags as indices. Technical vocabulary often poses a text mining challenge due to the rarity of its diction in the broader context. We introduce an extension to the common English vocabulary that allows for nearly-complete indexing of USDA Soil Series Descriptions.

\section{SUBJECT TERMS}

Soil science, Classification, Taxonomy, Databases, Text mining

\section{SECURITY CLASSIFICATION OF:}

\section{a. REPORT}

Unclassified

\section{b. ABSTRACT}

Unclassified

\section{c. THIS PAGE}

Unclassified
17. LIMITATION OF ABSTRACT

UU
18. NUMBER OF PAGES

11 19a. NAME OF RESPONSIBLE PERSON

19b. TELEPHONE NUMBER (include area code) 